\title{
Tratamento do Pé diabético com creme reestruturante
}

\section{Treatment of diabetic foot with restructuring cream}

\author{
Margrit Gabriela Wilke' • Valéria Choma Zagulski
}

\section{INTRODUÇÃO}

Estudos de 2014, apontam 9,2 milhões de adultos com diabetes no Brasil, sendo destes 829.724 pacientes portadores de pé neuro-isquêmico, com 43.726 com ulceras no pél. Estima-se que no Brasil existam 12,5 milhões de pessoas com o diagnóstico de diabetes2. Dados da Sociedade Brasileira de Diabetes-SBD, apontaram em 20I7, 4 milhões de mortes por diabetes no mundo, destes 209.717 adultos com idades entre 20-79 anos que morreram como resultado do diabetes. Metade dessas mortes foram no Brasil, sendo 44,9\% dessas mortes aconteceram em pessoas com menos de 60 anos de idade2. 2030, o Diabete Mellitus-DM pode saltar de nona para sétima causa mais importante de morte em todo o mundo4. Estima-se que um entre cada quatro pessoas com diabetes possa desenvolver problemas nos pés ao longo da vidal,3. O pé diabético engloba um conjunto de síndromes nas quais afecções neuropáticas, isquêmicas e infecciosas podem causar danos teciduais e, consequentemente, ulcerações e amputações. Segundo posicionamento Oficial da Sociedade Brasileira de Diabetes n 05/2019, baseada na Associação Americana de Diabetes, a polineuropatia diabética (PND), é a complicação que atinge 50\% dos pacientes, sendo a causa mais importante para as úlceras nos pés dos pacientes diabéticos, que precedem $85 \%$ das amputações. A PND leva a insensibilidade e nos estágios mais avançados, deformidades. A tríade PND + Deformidades + Trauma são fatores determinantes para o chamado "pé diabético", caracterizado por ulceração complicada por infecção e que pode evoluir para amputação, principalmente se há má circulação - a doença arterial obstrutiva crônica (DAOP) 3,4,5,6,7,8. Outras condições colocam a pessoa em mais alto risco: doença renal do diabetes (DRD), retinopatia diabética (RD), condição socioeconômica baixa, morar sozinho e inacessibilidade ao sistema de saúde. Segundo o Ministério da Saúde, 70\% das cirurgias para amputação de membros inferiores (pernas, pé, dedos dos pés) no Brasil têm como causa o diabetes mal controlado: são 55 mil amputações anuais $4,5,6,7,8,9,10$.

I. Bacharel em Enfermagem pela Faculdade São Camilo SP; Gestão em Saúde IBMEC São Paulo (2000); MBA em Gestão Financeira nas Organizações de Saúde - PUC SP (2002). Especialização em Enfermagem Dermatológica - Gama Filho;Título Enfermeira Dermatológica pela SOBENFeE (20I3). Profissional com 20 anos de experiência na área da saúde em empresas nacionais e multinacionais, com treinamentos Internacionais pela $\mathrm{KCl}$ - Costa Rica - Health Point- México e Paul Hartmann. Responsável pela estruturação de equipes técnico comercial para lançamento da pressão negativa em território nacional; desenvolvimento de treinamentos teórico-práticos para equipe interna, distribuidores e clientes finais. linkedin.com/in/Gabriela-wilke e-mail:mgabrielawilke@gmail.com

2. Bacharel em Enfermagem pela Faculdade Anhanguera de São José - SC (20I4); Pós-graduada em Estomaterapia pela Universidade do Extremo Sul Catarinense - UNESC (2016). Profissional com experiências em lesões de pele, estomaterapia, terapia por pressão negativa, cobertura de lesões de pele, assistência de enfermagem ao paciente, treinamentos no uso de cobertura para lesão de pele, e clínica médica e cirúrgica.Email:valzaz@hotmail.com 


\section{RELATO DE CASO I}

Paciente 40 anos, masculino, com histórico de DM desde a juventude, com lesão em Hallux E há II anos, com diversos tratamentos realizados, sem o fechamento adequado da lesão. Em uso de Bomba de Insulina, porém com grandes variações glicêmicas durante o tratamento. Antecedentes doença renal do diabetes (DRD), retinopatia diabética (RD). Figura I. Realizado desbridamento, aplicação do creme Hycos + curativo oclusivo, com troca diária pelo paciente. Figura 2. 34 dias após início do tratamento com Hycos, redução significativa do diâmetro da lesão, redução da queratose em bordos. Figura 3.03 meses após o fechamento da lesão.

\section{Caso I:}

Figura I - Início do tratamento*

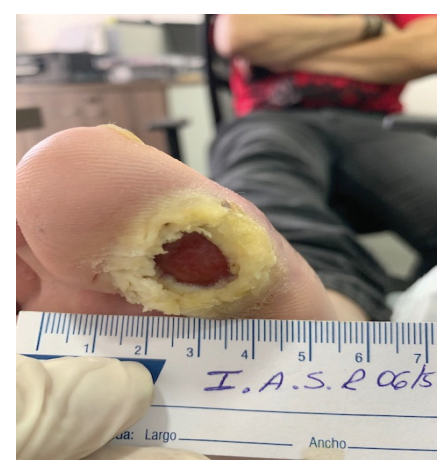

Figura 2 - 34 dias de uso do creme reestruturante*

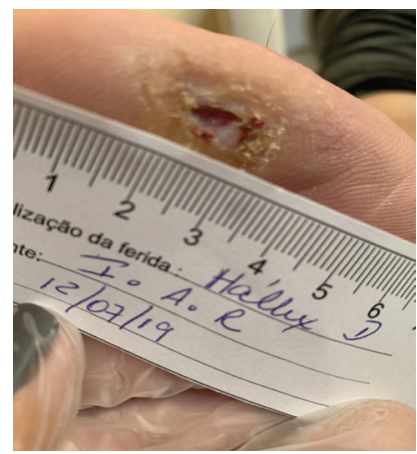

Figura 3 - 03 meses após fechamento da lesão*

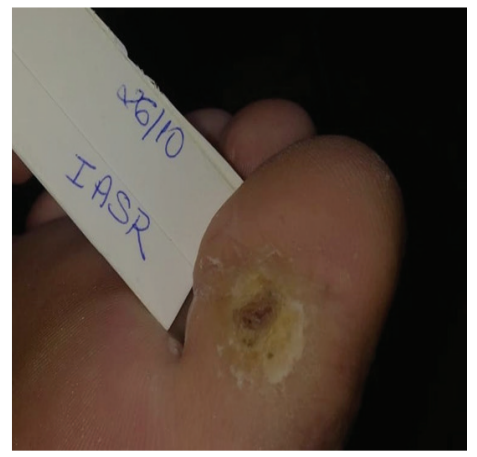

*Fonte: Os autores, 2019.

\section{RELATO DE CASO 2}

Paciente 36 anos, masculino, com histórico de DM há
10 anos, com lesão em hállux D há 03 anos, sem sucesso em tratamentos anteriores, afastado do trabalho devido lesão. Antecedentes hipertensão. Figura I.Realizado desbridamento e aplicação do creme reestruturante Hycos. Figura 2. Lesão com melhora significativa, em I5 dias de uso do creme reestruturante Hycos. Figura 3. Epitelização completa em 28 dias

\section{Caso 2:}

Figura I - Início do tratamento*

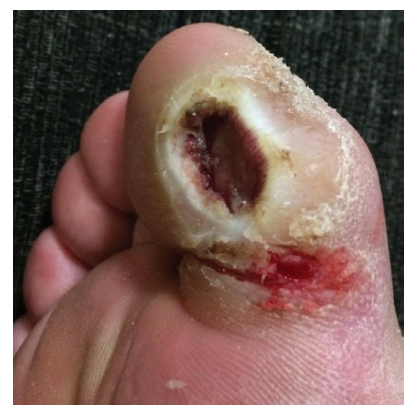

Figura 2 - 15 dias de uso do creme reestruturante*

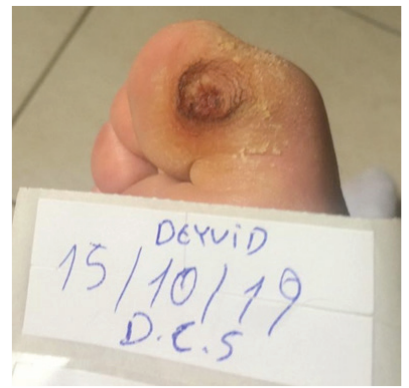

Figura 3 - 28 dias, fechamento da lesão após fechamento da lesão, pós desbridamento 01 out. 2019*.

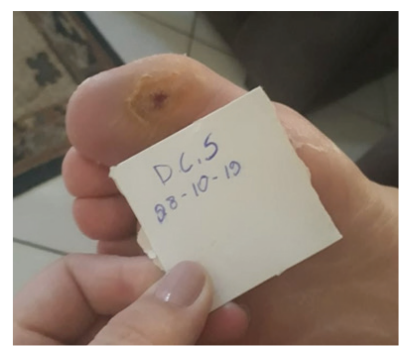

*Fonte: Os autores, 2019.

\section{DISCUSSÃO}

Sendo estimado que o Brasil é o $6^{\circ}$ pais do mundo em gastos com diabetes, e com as projeções de que o número de pacientes diabéticos poderá aumentar em todo o mundo, gerando impacto sócio econômicos é de fundamental importância que políticas preventivas, diretrizes educacionais e alternativas de tratamentos sejam encontradas. O tratamento e acompanhamento de pacientes com lesões nos pés diabéticos exige cuidados especializados, adesão do paciente e familiares ao tratamento 
proposto, sendo um desafio a equipe multidisciplinar. A reparação tecidual e epitelização levam longo tempo, trazendo altos custos aos pacientes. Fundamentada nos dados estatísticos apresentados, condições de longo tempo de tratamento dos pacientes com as lesões, a escolha do produto, creme reestruturante foi baseada na facilidade de uso do produto pelo paciente e familiares, reduzindo as consultas e curativos com os profissionais, baixo custo do produto, além dos princípios ativos naturais de sua fórmula no desbridamento autolítico, estímulo de angiosenese, manutenção do meio úmido, ação bactericida, ação fungicida e sem contra indicações.

\section{CONCLUSÃO}

O creme reestruturante Hycos, reduziu tempo de tratamento e se mostrou eficaz no estimulo a angiogêne$\mathrm{se}^{4,5}$, com cicatrização completa das lesões dos pés diabéticos dentro de 3-9 semanas. 


\section{REFERÊNCIAS}

I. Sociedade Brasileira de Diabetes. $O$ alto custo do pé diabético no Brasil. Disponível em: https://www.diabetes.org. br/publico/ultimas/ I609-o-alto-custo-do-pe-diabetico-no -brasil.Acesso em: 12 mar. 2020.

2. Sociedade Brasileira de Diabetes. Posicionamento Oficial SBD n. 0I/2019: Conduta Terapêutica No Diabetes Tipo 2: Algoritmo SBD 2019. São Paulo: SBD; 2019. Disponível em: diabetes.org.br/profissionais/images/2018/poster-atlas-idf-2017.pdf.Acesso em: 12 out. 2019.

3. Sociedade Brasileira de Diabetes. Posicionamento Oficial SBD n. 0I/2019: Conduta Terapêutica No Diabetes Tipo 2: Algoritmo SBD 2019. São Paulo: SBD; 2019. Disponível em: https://www.diabetes.org.br/publico/images/pdf/sbd_ dm2_2019_2.pdf.Acesso em: 12 out. 2019.

4. Brasil. Ministério da Saúde. Secretaria de Atenção à Saúde. Departamento de Atenção básica. Manual do pé diabético: estratégias para o cuidado da pessoa com doença crônica. Brasília: Ministério da Saúde; 2016.

5. Shaw JE, Sicree RA, Zimmet PZ. Global estimates of the prevalence of diabetes for 2010 and 2030. Diabetes Res Clin Pract 2010; 87(I): 4-I4. São Paulo. Secretaria Municipal de Saúde. Programa de prevenção e tratamento de úlceras crônicas e do pé diabético. Protocolo de preven- ção e tratamento de úlceras crônicas e do pé diabético. São Paulo; 2009.

6. Maia TF et al. $O$ pé diabético de clientes e seu autocuidado. Esc. Anna Nery R Enferm. 2005 Abr 9(I):95- 02.

7. Grossi SAA. Prevenção de úlceras nos membros inferiores em pacientes com diabetes mellitus. Rev. Ese. Enf. USP. 1998 Dez 3(4):377-385.

8. Sociedade Brasileira de Diabetes. Diagnóstico precoce do Pé Diabético. In: Sociedade Brasileira de Diabetes. Tratamento e acompanhamento do diabetes mellitus: diretrizes da Sociedade Brasileira de Diabetes. SBD; 2007. p. II7-II9. Disponível em: http://www.cff.org.br/userfiles/file/noticias/Diretrizes_SBD_2007\%5BI\%5D.pdf. Acesso em: 12 fev. 2020.

9. International Working Group on the Diabetic Foot. Diretivas práticas sobre o tratamento e prevenção do pé diabético: Com base no Consenso Internacional sobre o pé diabético. IWGDF; 20II.

10. Grupo De Trabalho Internacional Sobre Pé Diabético. Consenso Internacional sobre pé diabético. Brasília, DF: Secretaria de Estado da Saúde do Distrito Federal; 200I. 100 p.

Recebido: 2020-02-04

Aceito: 2020-03-10 